\title{
Survey of young offenders in a regional secure unit
}

\author{
C. Lengua, S. Handy and A. Dhariwal
}

\begin{abstract}
The management of young offenders by specialist peychiatric adolescent forensic services is currently the subject of considerable debate of the Royal College of Psychiatrists and at the Department of Health. It is important to know what has been done in dealling with this very important group of vulnerable young people. This study aims to delineate how medium secure units become involved with this group and what happens to them.
\end{abstract}

A number of studies have commented on the expansion of forensic services (Higgins, 1981; Bullard \& Bond, 1988). The Butler Committee recommended in 1975 an emphasis on community care and out-patient work (Home Office, 1975). Bluglass (1975) reported on the first 372 cases seen in his Birmingham-based department. Hambridge (1992) described a forensic psychology service. Mendelson (1992) described an overall regional forensic service and Hosty et al. (1994) described a forensic out-patient service.

The above services include assessments of young people. These are an important group who have received increasing recognition. The constantly changing legal, educational and health care systems set up to deal with young offenders are under regular review at different levels. The criminal statistics for England and Wales 1994 (Home Office, 1995) showed that $44.8 \%$ of those sentenced for indictable offences were under the age of 21 . The male peak age of offending remains 18 years and for females is 14 years. Furthermore, it is also recognised that young offenders have a wide range of neuropsychological vulnerability (Bailey, 1994). That some of these young people suffer from psychiatric morbidity is unquestionable (Lewis et al. 1979; Bailey et al, 1994).

No literature exists on how adult regional forensic services manage young people. This paper attempts to fill the gap by describing the referral pattern and overall management of young people referred to a regional forensic out-patient service.

\section{The study}

The West Midlands Regional Forensic Psychiatric Services serves a population of 5.5 million people. It includes five consultant teams based on the regional secure unit, the Reaside Clinic. Out-patients are seen at the clinic, at two outpatient departments in nearby hospitals, at other hospitals and at penal establishments.

This study describes a subsample of young forensic out-patients referred to the service between 1990-1992, before the establishment of the court diversion scheme in the Midlands in 1993.

All young people referred to the service under the age of 21 years were identified from the unit case register. The clinical notes of a subsample of this population seen by psychiatrists were then taken at random and scrutinised, including court reports. Sociodemographic, forensic and psychiatric information was recorded using a standard pro forma prepared by the authors. The pro forma also recorded family details, source and reason for referral, as well as the treatment and recommendations given by the assessing psychiatrist. When diagnoses were made, these were based on high clinical standards and were recorded as written in the clinical notes. Similarly when recording forensic histories, if more than one offence was noted, all the offences were recorded. Chi-squared statistics with Yates correction were used to assess significance.

\section{Findings}

\section{Sociodemographic variables}

One hundred and seventy-seven young people under the age of 21 were referred to the service between 1990-1992. Of this group, 80 young people were on remand either in prison or remand centres. Seventeen were sentenced prisoners (a ratio of 5 to 1). A total of 56 young people were surveyed. Of these, 49 were on remand and seven were sentenced (a ratio of 8 to 1 ).

The age range was 16-21 years with a mean of 16.5 years and a mode of 20 years. Fifty-one (91\%) were single; 42 (75\%) were unemployed: and $20(35.7 \%)$ were living with their parents. None of the sentenced young people were living with their parents at the time of conviction. Only four (7.1\%) of the sample were females. 


\section{Personal factors}

Sixteen (28\%) individuals came from singleparent families but the majority, 27 (48.2\%), came from nuclear families. Twenty-four (42.8\%) had a positive family history for criminality; 14 $(25 \%)$ had a history of alcohol misuse; and ten $(17.8 \%)$ had a history of psychiatric illness. There was a history of declared sexual abuse in five $(8.9 \%)$ cases but of declared physical abuse in $15(26.7 \%)$.

\section{Sources and reasons for referral}

The main referrers were defence solicitors for 42 (75\%) cases. Other referrer agencies included social services, prison medical officers and courts. In $18(32.1 \%)$ cases the purpose of referral was for general advice, but in $42(75 \%)$ cases it was for direct assessment for the courts. What was most striking about the referrals was the unspecified nature of the reasons for making such referrals.

\section{Psychiatric histories and diagnoses}

Fourteen (25\%) young people had a previous psychiatric illness, $13(23.2 \%)$ had had outpatient psychiatric care and seven $(12.5 \%)$ had been in-patients. Nineteen (33.9\%) had a past history of deliberate self-harm and three (5.4\%) had a current history of the same. Twenty-four $(42.8 \%)$ had misused alcohol at the time of the offence.

At the time of assessment, $38(67.8 \%)$ had no psychiatric diagnosis. When a diagnosis was made, personality disorder was mentioned in six (10.7\%) cases. Schizophrenia was mentioned in four $(7.1 \%)$ cases. Other diagnoses included pyromania, alcohol misuse, and learning disability in four (7.1\%) cases.

\section{Forensic histories}

At the time of referral, seven (12.5\%) cases were sentenced prisoners and the rest were on remand and in the process of being charged with a criminal offence. Forty-three $(\mathbf{7 6 . 6 \% )}$ young people had a past criminal history. In $36(64.2 \%)$ cases the age at the time of the first offence was in the range of 8 to 11 years (mean and mode 14 years).

The young people presented at assessment with a variety of offences, the commonest being acquisitive $(29 ; 36.7 \%)$, assaultative offences (21; $28.5 \%)$ and sex-related offences $(9 ; 11.4 \%)$.

\section{Recommendations}

The pro forma asked whether treatment was required and/or offered. The notes went some way towards establishing whether treatment was received.
It was felt that treatment was not required in $33(58.9 \%)$ cases and was not offered in 18 (32.1\%) cases. However, no recommendations were made in 27 (48.2\%) cases. Probation orders were supported in $10(17.8 \%)$ cases. Referrals to other services were made in seven $(12.5 \%)$ cases. to, for instance, drug rehabilitation teams, highrisk offender programmes, special prisons for psychiatric patients, and therapeutic communities. In three $(5.4 \%)$ cases (all of whom had schizophrenia) hospital admission was necessary. In cases of personality disorder, usually no recommendations were made, and on one occasion another psychiatric opinion was recommended.

\section{Comment}

As expected there was a preponderance of males, the great majority being on remand, and $75 \%$ of the sample being referred by solicitors. There are no normative data with which to compare these results other than those in the existing adult literature. In Mendelson's (1992) study and Hosty et als (1994) study, the percentages of people referred by solicitors to the service were 34 and $52 \%$ respectively. The two services have different practices to account for their differences. They both included young people in the analysis of their figures. What was most striking about the referrals in our study was the unspecified reason for making them.

Although the majority of young people seen had no psychiatric disorder at the time of assessment $(68 \%)$, a quarter of them had had previous psychiatric illness. As many as $43 \%$ of the sample had a history of alcohol misuse at the time of the offence. When diagnoses were made, the most common were personality disorder and schizophrenia.

No recommendations were made in almost $50 \%$ of cases. When they were made, there was a diverse range of recommendations to manage these young people. These included referral to other services $(12.5 \%$ of cases), occasionally arranging hospital admissions (7.1\%), or supporting probation orders (17.8\%).

Mendelson (1992) and Hosty et ats (1994) descriptions of the work of forensic psychiatrists in out-patient settings as being essentially that of preparing court reports is clearly true as far as young people are concerned. Whether this is the case because their service is not geared to deal with the problems that young offenders present is a question that needs answering. There certainly seems to be a subgroup of young people referred to the adult forensic psychiatric services who have particular characteristics and needs.

This is a time when there are considerations about the special management of young offenders by child and adolescent forensic psychiatric 
services. The work done so far by existing services needs to be taken into consideration to coordinate better alternative resources to the existing ones.

It has become increasingly evident that training in child and adolescent forensic psychiatry is important but difficult. There are few centres in the country that provide it. Forensic psychiatrists and child psychiatrists need to begin to share their expertise if they are to provide services to deal effectively with the problems of young offenders with mental health problems.

\section{Acknowledgement}

The authors thank Dr P. Vostanis for the advice given with this study.

\section{References}

BAILEY, S. (1994) Critical pathways of child and adolescent murderers. Chronicle of the International Association of Juvenile and Family Court Magistrates, 1. 5-12.

-. Thornton, L. \& Weaver, A. B. (1994) The first 100 admissions to an adolescent secure unit. Journal of Adolescence, 17, 207-220.

BLuglass, R. S. (1975) Forensic psychiatry services in the community. Joumal of the Irish Medical Association, 68. 453-459.
BULLARD, H. \& BOND, M. (1988) Secure units: why are they needed? Medicine. Sclence and the Law. 28. 312-318.

HAMBRIDGE, J. A. (1992) Referrals to an out-patient forensic psychology service. Psychlatric Bulletin, 16. 222-223.

HigGins, J. (1981) Four years experience of an interim secure unit. British Medical Journal, 282, 889-893.

HOME OFFice (1975) Report of the Committee on Mentally Abnormal Offenders (Butler Report). London: HMSO.

- (1995) Criminal Statistics England and Wales 1994. London: HMSO.

Hosty. G., COPE, R. \& DERHAM, C. (1994) 1000 forensic outpatients: a descriptive study. Medicine, Sclence and the Law, 34, 243-246.

Lewis. D. O., Shanok. S. S., Pincus, J. H., et al (1979) Violent juvenile delinquents. Psychiatric, neurological. psychological and abuse factors. Joumal of the American Academy of Child Psychiatry. 18. 307-319.

MENDELSON, E. F. (1992) A survey of practice at a regional forensic service: what do forensic psychiatrists do? British Joumal of Psychiatry, 160. 769-776.

*Cesar Lengua, Senior Registrar in Forensic Child and Adolescent Psychiatry, Reaside Clinic, Bristol Road South. Rednal B45 9BE; Sumy Handy. Senior Registrar in Child Psychiatry. Child and Family Consultation Centre, Stafford and Avi Dhariwal, Former Registrar at Irwin Unit for Young People, Birmingham

*Correspondence 